\title{
THINKING STRATEGICALLY ABOUT ASSESSMENT
}

\author{
Abstract \\ Drawing upon the literature on strategy formulation in organisations, this paper \\ argues for a focus on strategy as process. It relates this to the need to think \\ strategically about assessment, a need engendered by resource pressures, \\ developments in learning and the demands of external stakeholders. It is argued that \\ in practice assessment strategies are often formed at the level of practice, but that this \\ produces contradiction and confusion at higher levels. Such tensions cannot be \\ managed away, but they can be reflected on and mitigated. The paper suggests a \\ framework for the construction of assessment strategies at different levels of an \\ institution. However, the main conclusion is that the process of constructing such \\ strategies should be an opportunity for learning and reflection, rather than one of \\ compliance.
}

Keywords: assessment strategy

\section{Introduction}

Academics are frequently enjoined to think 'strategically’ about assessment (e.g. Gibbs, 1999), but rather less time is spent on defining what is meant by 'strategy' in this context. Brown, Bull and Pendlebury (1997), for example, are careful to decompose assessment practices into instruments, sources and methods, but it is assumed that strategy is not in need of such attention. This paper argues that we do, by contrast, have to think a little more carefully about what we mean by this term. It 
contends that without such attention we are in danger of confusing strategy with either assessment policies or assessment practices - or both. Briefly, to do the former can mean losing the critical reflection that is needed in favour of compliance, to do the latter is to loose all sense of direction and purpose. We draw upon arguments from organisational and management studies to argue for a processual-relational view of strategy (Watson and Harris, 1999). These arguments are used to frame what strategies might look like at different institutional levels. However, we start with a brief consideration of why thinking strategically about assessment might be particularly pertinent to current conditions. This consideration considers the growth of mass education, the spread of modularisation, the increasing impact of external stakeholders and the trends towards increasing diversity in assessment as converging elements in the need for a more strategic perspective.

It is possible to argue that there have always been assessment strategies, but that these have not been articulated. Assessment that relies entirely on unseen examinations, for example, rests on often tacitly held assumptions about the nature and purpose of both assessment and learning. Such assumptions were often inculcated by processes of academic socialisation that operated at a primarily social level. Such socialisation was feasible when staff numbers were small and opportunities for contact high. The assessment practices that emerged were assumed to meet the needs of students who were participating as part of an elite. Of course this picture is a caricature and there were challenges to this situation from both sides. However, the dramatic growth of higher education means that there are rather fewer opportunities for the spread of tacit knowledge. Assumptions about assessment need to be formalised and articulated, so that they can be debated amongst a much larger staff constituency. Staff are also 
likely to be have drawn from a much greater range of backgrounds, particularly in modern universities where recruitment is often on the basis of commercial, industrial or professional expertise. Such recruits will not have undergone the long process of socialisation into academic norms. These norms, therefore, need to be articulated so that they are made available for critical reflection and debate.

In turn, these staff are increasingly likely to be teaching on modules rather than 'courses'. In large, inter-disciplinary programmes their input is likely to be one amongst many. As well as making it difficult to build a sense of course 'identity', such moves further erode the informal sharing of experiences that marked successful courses. The consequences of modularisation, as far as assessment is concerned, appear to be fragmentation and over-assessment - or at least these are new possibilities (Brown, Bull and Pendlebury, 1997). These point to the need to create strategies at the programme level that seek to overcome these problems. However, such strategies are not necessarily directly related to modularisation in the sense of needing consistency so that students can mix modules across an institution. In practice, such possibilities seem limited. Rather, modularisation makes the environment in which assessment practices occur rather more fluid, with students experiencing a greater range of methods and approaches (Webster, 1992). It is often the student who has the better overview of this experience. Given option choice it is often difficult to get a 'typical' pattern, but steps need to be taken to get some consistency of assessment practice - for example, in workloads and deadlines - across modules. This implies that guidelines need to be supplied at a number of institutional levels, that, in Brown et al's words, 'departments and schools reflect upon their 
approaches to assessment with a view to easing assessment loads and improving their effectiveness.' (Brown, Bull and Pendlebury, 1997: 57)

Such injunctions, however, stop short of the level of the institution itself, but an institution can play a crucial role in providing frameworks within which its organisational units can operate. Of particular importance here is the need to be alert to and interpret the demands of a growing number of external stakeholders. Of course, external parties, such as professional bodies, have always been interested in the shaping of assessment patterns. However this has tended to be at the programme level, with negotiations entered into about the pattern of assessment needed to gain exemption for students from elements of professional accreditation. This rather local focus has been supplemented in recent years by a more holistic focus, notably as articulated by the Quality Assurance Agency in its Code of Practice (http://www.qaa.ac.uk). Such guidance demands an institutional response, and not only because QAA auditors might expect such a response. The institution needs to define its stance towards such codes and suggest how they are to be interpreted throughout the institution. In many cases, it might want to be more directive than this, and to overrule local custom and practice. This immediately sets up a tension that is best handled by a formal articulation of strategic principles than by procedural imposition.

This growth of external interest in the nature and purpose of assessment can also be seen to have influenced another trend with implications at all levels of an institution. This is the trend towards greater diversity in assessment. Fuelled by resistance to the traditional approaches outlined above, this has happened principally at the level of 
methods, with a range of new approaches being tried out at the operational level. Of particular importance has been the shift away from the traditional pattern of essays and unseen examinations. Glasner’s review of quality inspection reports concludes that, despite variations by subject and institution, 'the pattern of assessment experienced by today's undergraduate and postgraduate appears to be more likely to involve a variety of coursework components as well as examinations than that of students of even a decade ago.'(Glasner, 1999: 22). However, without some strategic direction this trend is likely to simply reinforce fragmentation of the student experience. Issues of progression between levels and consistency across levels - for example, in the nature and type of written work required - become more important when students may be facing unfamiliar assessment methods. There is a need to consider a range of ways in which to prepare students for such methods. These can range from the provision of detailed criteria within modules that clearly explain what is expected from assessment to consideration of progression from level to level. In the latter case, we might want to ensure that students do not meet a particular form of assessment at an advanced stage of their studies that they have not encountered earlier, if such assessment requires a degree of familiarity and practice for successful performance. Again, the pressure seems to be for more clearly defined strategies at the programme level, but as Brown and Knight (1994) argue, there are implications at a broader level. ' We do think', they suggest, 'that students should expect to develop a range of problem-working, communication and critical thinking faculties, and that it is not acceptable that only students in certain departments are assessed on those achievements, for that implies that only in those departments are those abilities taken seriously.' (Brown and Knight, 1994: 124). Again, the issue of strategic thinking is 
important at a variety of levels, so it seems appropriate to think through what might be involved in such a process.

With refreshing directness, Brown, Bull and Pendlebury (1997: 230) admit, 'The development of the optimal strategy for a university is well beyond the scope of this book.' They do suggest some features of such a strategy (balancing efficiency, effectiveness and enablement) but their approach seems typical of much of the literature giving advice on assessment, in that it does not engage with the issue of what strategy is. Graham Gibbs highlights the essential difference when he points out that "Much of what is presented as good practice in assessment is described in terms of tactics: specific techniques such as using criteria on feedback sheets to students. This chapter is about using assessment strategically, regardless of specific tactics, to achieve particular strategic goals’ (Gibbs, 1999: 41). However, this approach is confined to the level of the module. Work that suggests that it will be considering the issues at a higher level, such as Sally Brown’s (1999) ‘Institutional Strategies for Assessment', turns out to be considering broad approaches to assessment in which the term 'strategy' is not defined. Such work as exists which attempts to consider assessment at different levels draws on systems theory, notably the work of Peter Knight and Mantz Yorke (Brown and Knight, 1994; Knight and Trowler, 2000; Yorke, 1998; Knight, 2000). This paper is not the place to engage in a detailed critique of systems thinking, but there are elements in this tradition that can lead to a rather mechanistic, control orientation. The suggestion in the argument presented here is that drawing upon the discourse of strategy promises to be much more fruitful. 
Now, it is recognised that the mention of such terms will be anathema to many, smacking as it does of the further colonisation of the academic lifeworld by managerialism $^{1}$ - and the writer of this paper shares these concerns ${ }^{2}$. However, this need not be the case if we make it clear about why we are drawing upon these sources. Firstly, the ideas outlined here are taken from the literature in organisational and management studies, not from managerialist practices directly. This is by no means a homogeneous body of thought and there is a small but growing area of ‘critical management studies' (Alvesson and Willmott, 1996). It is on the more critical works that this paper draws, with a view not to importing concepts directly, but using them to think about assessment. One of the main trends within thinking about management and organisations is towards a 'processual-relational' view (Watson and Harris, 1999). This argues that we are not concerned with mechanistic views of entities as static phenomena, but dynamic analyses of emergence. Such a perspective is particularly critical of the control orientation of much systems thinking and this informs the discussion of strategy that follows. In the rather ugly words of this discourse, the concern is more with 'strategising' as a process than of strategy as a product. In practice, as we shall see, we need to consider both. However, the value of this approach is its emphasis on learning at different organisational levels. The review that follows looks at 'classical' views of strategy formation, stressing their emphasis on the future and the external environment. This has some value in the context of assessment, but a number of problems - the association with planning, links with hierarchy and the divorce from practice - are highlighted. This then leads us into a consideration of alternative approaches that look at emergence and internal competence as crucial dimensions of strategy formation. This might be seen as complementary to the focus on the organizational change literature in the HEFCE 
guide to institutional learning and teaching strategies (HEFCE, 1999). Whilst quite properly drawing attention to differences between higher education institutions and private sector organisations, this might be argued to present too unitary a view of change in the latter. That the process of organisational change is not one of executive fiat is demonstrated in work such as that of Pettigrew (1985) on ICI. Again, the importance of such work is of a focus on process within the constraints provided by particular contexts.

\section{Approaches to strategy}

In the 'classic' view of strategy the twin concerns are the future and the external environment. ${ }^{3}$ An organisation needs a sense of where it going and what forces in its environment are going to help or hinder it in achieving this goal. The 'positioning' school associated in particular with the work of Michael Porter (1985) is particularly significant here. He suggests a number of frameworks that examine generic components of an organisation' s environment. This literature is replete with four-box matrices and checklists which organisations complete to position themselves against a limited number of possible strategies. The strengths of this approach are that it does suggest that organisations need to take their environment seriously and that to do so they need a 'model' of how their actions are going to affect that environment. In broader terms they need a theory of the world in which they operate, and this would seem to be relevant to assessment. What is required is that, as Brown (1999: 3) argues, 'the assessment strategies we use must be a result of conscious decisions based on informed choice.' Such choice implies some basis on which to make that choice. Of course, we need to recognise the often-competing purposes of assessment - 
to confer an award, to rank students and to aid learning - and that this will complicate choice. However, for this argument the focus is on student learning and so the appropriate theory is one of learning and how assessment affects this. However, theories of learning tend to be relatively silent about the impact of assessment. Michael Reynolds and Kiran Trehan (2000) point to the way in which critical approaches to learning often use 'traditional' methods of assessment without thinking through the contradiction between the assumptions behind such methods and the espoused learning objectives. Similarly, Kieran Egan (1997: 272) concludes a stimulating discussion on ways of understanding and how learning can develop these with the rather bathetic statement that 'We will, of course, want evidence that students have learned the content that has made up the lesson or unit of study; this can be achieved through traditional techniques.' So we cannot simply 'read off' assessment practices from particular approaches to learning. More work is clearly needed here, but the classical school of strategy making reinforces this need for conscious choice.

However, using this language raises one of the key objections to its approach, for it is firmly located in the 'rational' school of decision making. In this school, our task is to gather information by clearly defined (often quantitative) analytic techniques and to apply structured decision making tools to the results. This as been critiqued on a number of levels. Some writers point out that it assumes organisations as passive observers of their environment, underplaying the extent to which organisations 'enact' their environments (Daft and Weick, 1984). This suggests a creative role for the interpretation of the view of external stakeholders. The emphasis on analysis tends to elevate the position of strategic planning from a necessary but subordinate component of the process into the dominant force. Not only does this absorb a disproportionate 
amount of time and organisational energy, but it tends to reduce implementation to a matter of following detailed blueprints. In the context of assessment, this is what can happen when strategy is narrowly conceived of in terms of policies and procedures. These are vital in large and complex institutions, but they should flow from a clear set of principles rather then substituting for them. Without such clear articulation of principles, the result is likely to be compliance rather than creative and imaginative application. Further, the strategic planning approach tends to associate the business of strategy with a limited group of specialised staff at the top of organisations. Critical accounts of organisational strategy making have noted how the word 'strategy' is used as a rhetorical device to secure legitimacy for particular approaches (Alvesson and Willmott, 1996). In this process, issues of practice as treated as 'mere' operational 'details'. The result in practice is for strategic pronouncements to be grudging complied with or actively sabotaged. This might give us pause for thought if we are tempted to see assessment strategies as attempting to bring in common practice across an institution, as we will see below.

Many critiques of the planning approach have seen a focus on an alternative 'resource-based' view of strategy. This places a particular emphasis on the competences available to the organisation, both in its organisational knowledge of its environment and potential and in the staff working for the organisation at all levels. Without the active involvement of such staff, strategies will remain as empty documents. Resource-based approaches build on experience of strategies that suggest that they are often emergent. That is, they emerge from a stream of decisions which taken cumulatively change the direction of the organisation. Successful organisations are those that can provide the environment for such emergent processes, recognise 
them when they occur and generalise the learning throughout the organisation. This places a good deal of emphasis on strategy as an on-going dynamic process rather than the production of a once- and -for-all output. It also stresses the importance of learning at all levels of the organisation in a constantly iterative process between different levels. Work on organisations indicates the existence of different ways of strategic knowing depending on local cultures (Sackmann, 1991). The focus on strategic planning tends towards the suppression of such local difference, with an emphasis on common meanings. A more 'ecological' approach to the use of information suggests the need to be conscious of such local meanings but to support their mutual articulation (Davenport, 1997). Different local practices may be a valid response to the needs of that local context. In terms of assessment, this means that institutional strategy ought not to be about the imposition of uniformity. This is to go beyond Knight and Trowler's (2000) recognition of the importance of the 'department' as a structural quantity towards the centrality of ways of knowing in particular subject areas (Lea and Street, 1998). It is only at these levels that meanings can be shared and debated. However, a focus on emergence does not mean that institutional level issues are to be ignored. Rather there is a role in coordination of the learning that emerges from local practice and the provision of a framework within which that learning can occur.

\section{Thinking strategically about assessment}

This brief review of the burgeoning literature of strategy formation gives us some assistance in thinking about assessment strategically. It enables us to suggest some generic features of assessment strategies, to consider the inter-relationship between 
strategies, policies and procedures and practices. Finally, it allows us to consider the features of an assessment strategy at different levels of an institution. From the classical view of strategy we can take the need to articulate the assumptions on which strategies are based. In the focus on the future, we take the need to consider why we are assessing and what we hope to achieve by it. This forces us to clarify our thinking about the multiple purposes of assessment and to choose our relative priorities. In so doing, we need to take account of theories of learning and the place of assessment in them. We might still come up with a 'traditional' pattern, but at least we will be able to justify this as the product of critical reflection. In the focus on the external environment, we find encouragement to look at the overall student experience, not just the picture from the module or subject perspective. The product of such reflection might well be a written document, but the value of the process is the learning in producing this, rather the product itself. From the resource-based approaches we can take the focus on strategy as a dynamic process in which the needs of control and order should be subordinated to creativity and critical reflection (but not thereby eliminated). Strategies therefore need to encourage learning and reflection at all levels in the organisation. In particular, they need to allow for the recognition and managing (not managing away) of tensions. The particular tension that is evident in modular schemes is that between the module and the programme, but other tensions exist within and between levels. As a consequence of this, we suggest the following definitions:

Take in figure 1 about here ${ }^{4}$

The definition of practice indicates the inter-relationships (and often tensions) between these elements at different levels of the institution. As much of the focus of the literature is on the module level, this treatment reverses the emphasis by starting at 
the level of the institution. When we talk about institutional strategies we are often tempted into attempts by an organisation to specify practice at quite a detailed level. Often inspired by particular examples (notably Alverno College in the USA (http://www.alverno.edu/)) and by the discourse of staff development, these envisage a more dirigiste role for the centre (Yorke, 1998). Whilst it is not specifically about assessment, the definition offered by Gibbs, Habeshaw and Yorke is a useful summary:

Strategic: in which a co-ordinated set of goals concerned with learning and teaching, and mechanisms for achieving them, were pulled together across a range of activities which had a common focus on teaching and learning (Gibbs, Habeshaw and Yorke, 2000, 360).

It is interesting to note that this is derived from a review of teaching and learning strategies submitted to the Higher Education Funding Council for England and that this definition appears to explain an analysis of 'organisational models'. In carrying out this analysis, the authors explicitly contrast it to the 'devolved' model, which they see as at being at the other end of a continuum. The definition here is a model 'in which departments or sub-units were responsible for developing their own strategies, with or without central policy, goals or monitoring' (Gibbs, Habeshaw and Yorke, 2000, 359). What might be problematic about this distinction is that it could be taken as assuming that strategy is the same as central direction, as opposed to the central stating of principles. We could argue that the former is problematic at a number of levels. One is that experience from small, cohesive institutions is difficult to generalise to larger, more complex institutions. More important is that it is both 
inappropriate and impractical. Inappropriate, because it ignores the local specificity of assessment practice. This is not to deny the generalisability of theories of learning at an abstract level, but these have to be mediated through the lens of the particular subject. Impractical because, as Knight and Trowler (2000) has argued, the organising centre for academics is at the local level, in their case at the level of the department. An institutional strategy that relies on central direction alone is unlikely to work.

However, this is not to argue for institutional abstention. Far from it, as the example which the institution sets can be vital in setting the tone for actions at a lower level. A strategy that emphasises guidance and critical reflection, modelling these in its use of language, stands a better chance of encouraging similar responses than one that focuses on procedural issues. So an institutional strategy should focus as a priority on setting out guiding principles. This should be derived from its organisational mission and should weave this and its interpretation of external demands, such as subject benchmarking and codes of practice, into guidance that can inform the crafting of complementary strategies at all levels of the organisation. Within this, the institution needs to lay out those areas that are its responsibility as an awarding body and which cannot be further devolved. This forms the basis for the procedures that flow from the strategy, chief amongst which will be the assessment regulations. It still remains the responsibility of the institution to set out the conditions under which it awards qualifications and the standards that all constituent parts ought to follow. Likewise, it will want to specify the conditions for the validation and review of awards. However, the strategic principles ought to inform these conditions, so that validators maintain the distinctive assessment philosophy that the institution adopts. Data management is a further part of the operation of assessment that it seems sensible to retain at the 
centre (Miller, Imrie and Cox, 1998). This can be seen narrowly as the provision of data for the construction of performance indicators for institutional and external use. It is recognised that such data is required, but to concentrate solely on this would be dangerous. A central part of being critically informed at all levels is the use of data about assessment (not just results, but types and methods) to analyse practice. The provision of such data, along with the means to analyse it, is best handled centrally ${ }^{5}$. Finally, such means are not restricted to technical tools, but apply to the use of theoretical and practical understanding as applied to the assessment process as a whole. An institutional strategy needs to think about the role of the institution in supplying the resources to enable such learning to happen at all levels. It also needs to consider a process for monitoring what is happening that goes beyond the use of narrow performance indicators and reinforces the need for accountability and ownership of all levels of the institution. In doing this, it needs a reporting system that emphasises the need for critical reflection and not mere compliance, with the prime purpose of such reporting being action at the local level.

It gets rather harder to specify what this 'local level' might be with the growth of 'mode 2' knowledge. This term is used by Gibbons et al (Gibbons, Limoges, Nowotny, Schwartzman, Scott, and Trow, 1994) to indicate the growing importance of problem-focussed knowledge, as opposed to the discipline based knowledge of 'mode 1'. Such trends rather tend to undermine Knight and Trowler’s (2000) use of the 'department' as if it were the sole organisational focus. In some areas (notably business) the key organisational arena is the Faculty. In others, subject organisation below the level of the Department might be the crucial site. However, at a level that is above that of the programme it is useful to specify those aspects of academic 
performance that transcend programme or module boundaries. It can be useful to think here of the focus as on the individual practice of academics themselves. For example, at this level we would expect some consideration of feedback practices, with the establishing of clear guidance that all academics follow, regardless of programme. This emphasis suggests that at this level that we would expect a much greater emphasis on the specification of procedures. Some strategic consideration is still necessary. For example, it seems appropriate at Faculty level (to use that term as shorthand for Faculty/Department/Subject) to establish principles about accreditation for professional qualifications to enable programmes to place their strategies in a consistent framework. However, more attention might be expected to be given to the interpretation of procedures to provide guidance informed by a more detailed knowledge of local circumstances. This might need to be multi-layered depending on the organisational arrangements in effect. In large Faculties, with disparate departments, then the strategy at Faculty level might be to devolve most issues to the departmental level.

At a programme level, the key strategic question is the way in which assessment tests the learning outcomes for the programme as a whole. The achievement of such a target is made much harder by the whole process of modularisation, particularly at undergraduate level. Postgraduate programmes tend to be smaller with a more cohesive programme team, often united by common research interests. In this environment, agreement on how assessment looks from the perspective of the programme can be easier to achieve. However, as Boud (1995:43) points out the diversity of assessment 'means we must inevitably look at the profile of assessment as students see it, from the point of view of the course, the total experience of the whole. 
The move to modularised courses which operate as a smorgasbord makes this task much more difficult, but it is a challenge which must be faced.' We can recognise that in many institutions such courses operate with tightly defined cores and limited option choice, but the important issue here is not formal course structures, but the way in which they can be built up from a variety of modules. In many cases, it is suggested, the shift towards modules has meant a fragmentation in academic thinking and organisation, in which a coherent course view is difficult to establish and maintain. The challenge is to respect academic autonomy but at the same time to address fundamental issues such as progression between levels and consistency across levels. It means thinking about whether group work is desirable and what sort of balance might be desirable between different types of assessment. These are not issues of administrative detail, to be read off from tables of modular assessment, but matters of assessment principle.

Of course, in stating this we are drawing attention to the central tension between programmes and modules. Assessment needs to be linked to the learning desired in each module as a learning experience. The drive for innovation has often come at this level and patterns of diverse assessment emerge from concrete practice at the module level. However, if students are not to suffer from a fragmented assessment experience (no matter how good the individual parts) then there needs to be an overall framework within which it takes place. Moore (1995: 136) comments that:

while giving due recognition to the high degree of particularity of tutors' teaching and assessment roles, it is also difficult to see how from the viewpoints of quality and accountability universities can avoid setting firm 
and explicit institution-wide boundaries on the role of tutors in assessment, and thus provide more robust policy and practical frameworks within which course and departmental tailoring can be constructively accommodated.

The critical reflection that we expect of academics at the module level has to be informed by an awareness of the broader context in which they operate. This reinforces the need for clarity in processes at all levels. A summary of this is presented below:

Take in figure 2 about here

\section{Conclusion}

This paper has suggested that a tighter definition of what we mean by 'strategy' in the context of assessment can help in informing our practice. It can act as a counter to the tendency of the literature on assessment to focus on concrete practices and to pay rather less attention to the institutional context in which these occur. Such a focus is entirely understandable, but work in this area suggests that excellent practice in isolation can be negated by the overall context in which it takes place. As Boud (1995: 39) argues:

Students experience the interaction effects of one form of assessment on another. In any given month they may have to complete ten assessment tasks, in another month only one. The ways in which they approach each of these will be influenced by the others. A task which is intrinsically interesting and which may be approached meaningfully at any other time may be given short shrift when it is located among a thicket of examinations. Very little attention has been given to the compounding effects of assessment even when we know 
that it is the total array of demands in a given period which influences how each one is tackled.

This suggests clearly the need for frameworks at different levels of an institution and this paper suggests ways of formulating such frameworks. The key feature to emerge from a review of the literature on business strategy is the need for more focus on the process of strategy formulation. This is not to argue that the production of an articulated strategy is unimportant, nor to downplay the importance of clearly drafted procedures. However, it is to argue that the process of the creation of these products is a dynamic and iterative process that gives an opportunity for learning. The encouragement of such learning and the provision of a framework for its realisation could be the most important feature of an institutional assessment strategy. The greatest threat to such a process lies in the continual pressure on resources. At some points the expansion of numbers has qualitative impacts on what can be achieved in terms of assessment. In such circumstances it would be hardly surprising that staff fell back on methods of assessment that simply allowed them to cope. If a strategy is to be more than just coping, then the question of adequate resources has to be kept at centre stage.

\section{Acknowledgments}

My thanks to colleagues at Nottingham Business School for comments on earlier drafts and to an anonymous referee for perceptive comments given in a helpful fashion. 


\section{References}

ALVESSON, M., and WILLMOTT, H. (1996) Making Sense of Management. A Critical Introduction. (London: Sage).

BOUD, D. (1995) 'Assessment and Learning: Contradictory or Complementary', in:

P. KNIGHT (Ed.) Assessment for Learning in Higher Education (London: Kogan Page).

BROWN, S., and KNIGHT, P. (Eds) (1994) Assessment in Higher Education. (London: Kogan Page).

BROWN, G., BULL, J. and PENDLEBURY, M. (1997) Assessing Student Learning in Higher Education. (London: Routledge).

BROWN, S. (1999) 'Institutional Strategies for Assessment', in: S. BROWN and A.

GLASNER (Eds.), Assessment matters in higher education (Buckingham: Open University Press).

DAFT, R. L. and WEICK, K. E (1984) 'Toward a Model of Organizations as Interpretation Systems', Academy of Management Review, 9(2), pp. 284-295.

DAVENPORT, T. H. (1997) Information Ecology. (Oxford: Oxford University Press).

EGAN, K. (1997) The educated mind: how cognitive tools shape our understanding. (Chicago: University of Chicago).

GIBBONS, M., LIMOGES, C., NOWOTNY, H., SCHWARTZMAN, S., SCOTT, P. and TROW M. (1994) The New Production of Knowledge: The Dynamics of Science and Research in Contemporary Societies. (London: Sage). 
GIBBS, G. (1999) 'Using Assessment Strategically To Change the Way Students

Learn'. in S. Brown and A. Glasner (Eds.), Assessment matters in higher education

(Buckingham: Open University Press).

GIBBS, G., HABESHAW, T. and YORKE, M. (2000) 'Institutional learning and teaching strategies in English higher education', Higher Education, 40, pp. 351-372.

GLASNER, A. (1999) 'Innovations in Student Assessment: A System-wide

Perspective', in: S. Brown and A. Glasner (Eds.), Assessment matters in higher

eduaction (Buckingham: Open University Press).

HIGHER EDUCATION FUNDING COUNCIL FOR ENGLAND (HEFCE) (1999)

Institutional learning and teaching strategies: a guide to good practice. (London:

HEFCE).

KNIGHT, P. (1995) Assessment for Learning in Higher education. (London: Kogan Page).

KNIGHT, P. (2000) 'The Value of a Programme-wide Approach to Assessment', Assessment \& Evaluation in Higher Education, 25(3), pp. 237-251.

KNIGHT, P., and TROWLER, P. (2000) 'Department-level Cultures and the Improvement of Learning and Teaching', Studies in Higher Eduaction, 25(1), pp. 6983.

LEA, M., and STREET, B. (1998) 'Student Writing in Higher Education: an academic literacies approach', Studies in Higher Education, 23(2), pp. 157-172.

MILLER, A., IMRIE, B., and COX, K. (1998) Student Assessment in Higher

Education: a handbook for assessing performance. (London: Kogan Page).

MINTZBERG, H. (1994) The Rise and Fall of Strategic Planning. (Hemel

Hempstead: Prentice Hall). 
MOORE, I. (1995) 'Staff and Educational Development for Assessment Reform: A

Case Study’ in P. KNIGHT (1995) Assessment for Learning in Higher Education,

(London: Kogan Page).

PETTIGREW, A. (1985) The Awakening Giant: Continuity and Change in ICI,

(Oxford: Blackwell).

PORTER, M. (1985) Competitive advantage: creating and sustaining superior performance, (New York: Free Press).

REYNOLDS, M., and TREHAN, K. (2000) 'Assessment: a critical perspective', Studies in Higher Education, 25(3), pp. 267-278.

SACKMANN, S. (1991) Cultural knowledge in organizations: exploring the collective mind. (Newbury Park, Ca: Sage).

WEBSTER, F (1992) ‘Thinking strategically: a subject group’s attempts to maintain quality with reduced resources’, in: G. GIBBS and A. JENKINS (1992) Teaching large classes in higher education, (London: Kogan Page).

WATSON, T., and HARRIS, P. (1999) The Emergent Manager. (London: Sage). YORKE, M. (1998) ‘The Management of Assessment in Higher Education’, Assessment \& Evaluation in Higher Education, 23(2), pp. 101-116.

\footnotetext{
${ }^{1}$ By 'managerialism' is meant a form of thinking that assumes that the application of management techniques without an examination of their underlying assumptions is both necessary and likely to produce satisfactory outcomes. Such thinking is often associated with popular 'how to' books and an unthinking transfer of management models from the private sector to other areas of activity.

${ }^{2}$ Although see the brief discussion from sociology in Webster (1992) which uses the notion of 'thinking strategically' explicitly - though at the subject level and without defining strategy.

${ }^{3}$ The following discussion draws heavily upon Henry Mintzberg's (1994) Rise and Fall of Strategic Planning; rather than giving extensive references to the strategy literature, the interested reader can use this extensive references in this work. ${ }^{4}$ A note on terminology is needed at this point. In the organisational strategy literature the word 'policy' to cover the vision and basic goals has tended to fall into disuse. It would tend to be used, if at all, for the guidance that flows from the determination of the strategy. However, to use this term in this framework would tend
} 
to cause confusion, given that 'policy' tends to be used for broad principles in general higher education usage. Accordingly, this framework uses the term 'procedures' to cover the broad category of guidance that flows from the determination of strategic principles. In this, it is to be seen as having a wider meaning than 'regulations', which will form an important sub-set of procedures.

${ }^{5}$ This is largely for practical reasons, such as the expense of hardware and the availability of expertise. There is an argument for local data sets feeding into central data stores, but this is not the place to rehearse such refinements. As a minimum, the institution has to ensure itself about the quality of data on which assessment decisions are taken. 